\title{
Variation in Seedling Germinationand Growth in Five Populations Ofvitellariaparadoxa C.F. Gaertn.subsp. Nilotica: A Threatenedusefulfruit Tree Species in Uganda
}

Juventine Boaz Odoi ( $\nabla$ juventineboaz@gmail.com )

Makerere University College of Agricultural and Environmental Sciences

Thomas L. Odong

Makerere University College of Agricultural and Environmental Sciences

Clement Akias Okia

World Agroforestry (ICRAF)

JohnBosco Lomoris Okullo

Makerere University College of Agricultural and Environmental Sciences

Moses Okao

Ngetta Zonal Agricultural Research and Development Institute

Harriet Kabasindi

Busitema University - Namasagali Campus

Alice Muchugi

World Agroforestry (ICRAF), Nairobi

Samson Gwali

National Forestry Resources Research Institute (NaFORRI)

Research

Keywords: Ethnovariety, plantlets, root collar diameter, leaf size index, population, cluster

Posted Date: June 18th, 2020

DOI: https://doi.org/10.21203/rs.3.rs-35471/v1

License: (c) (i) This work is licensed under a Creative Commons Attribution 4.0 International License.

Read Full License 


\section{Abstract}

Background: We studied seedlings germination and growth performance in an economically and socially important fruit tree species of Vitellaria paradoxaC.F. Gaertn.subsp. nilotica (Kotschy) in Uganda. The study aimed at determining variability in germination of the five shea tree seed lots and seedlings growth performance based on their growth traits. Five populations were considered from four agroecological zones of Uganda and 180 candidates plus trees (16 ethnovarieties) selected as seed trees based on their traits for faster growth and high oil yield. A total of 1204 biological seeds were collected and sown in a general tree nursery at Ngetta Zonal Agricultural Research and Development Institute (NgeZARDI)during the month of June 2018 in a randomized incomplete block design with three replications.

Results: Significant variation $(X=526 ; p<0.01)$ was observed in seedling phenotypic traits within and between populations. Regression equation for height growth and leaf size index were given asy $=0.3787$ $+12.671 x$ and $y=0.6483+15.413 x$ respectively. Root collar diameter was more correlated to leaf size index (0.425) than to height growth (0.30). Clustering of shea tree seedlings based on phenotypic growth traits revealed one aggregated cluster indicating that most of the seedlings from the five populations were similar (Jaccard index 0.92, $p<0.01$ ). However, clustering based on SNP markers revealed three different populations. We recorded higher growth $(X=708 ; p<0.001)$ in Arua shea population (19.69 $\mathrm{cm})$ compared to the population average $(19.04 \mathrm{~cm})$. Red seeded; thin pulped and hairy fruited shea tree ethnovarieties assumed faster growth than the rest.

Conclusions: The phenotypic analysis of shea tree seedlings revealed some fast-growing genotypes from the five studied populations. Thesegenotypes can be selected for faster growth for shea tree breeding in Uganda.

\section{Background}

Shea tree (Vitellaria paradoxa) is a commercially useful indigenous fruit tree species found within Sudano-Sahelian Africa growing within a region of $600-1400 \mathrm{~mm}$ of annual rainfall (Boffa et. al., 2000). It grows up to $20 \mathrm{~m}$ in height. It plays economic, ecological roles and as supplementary food to the communities where it grows (Jasaw et al., 2015). The tree's importance is derived from a number of useful products it provides which include: oils, tasty fruits, cosmetic and medicinal ointments, soaps, income, fuels as well as various services (Gwali et. al. 2012). The fruit pulp is consumed by the communities in the shea growing areas and is therefore important in subsidizing household food and nutrition. It is mostly consumed before or as a substitute for the main meals. Infact the species is now considered a traditional African species whereby its nutritious fruit makes it a good source of food improving nutrition and boosting food supply during "annual hunger season"(Byakagaba 2013). The fat/oil is highly traded both locally and internationally for cooking, chocolate and cosmetics industries. The tree also plays a major role in nutrient recycling when the leaves and fine roots decompose although the leaves decompose at a low rate (Bayala et al., 2006). 
Shea trees grow mainly in northern, eastern and west Nile regions of Uganda where they greatly contribute to the community's livelihood, mostly women and children. Despite of its importance, the tree remains undomesticated probably because of its slow growth or lack of tradition to plant indigenous tree species (Asante et. al., 2012 and Pauliot et al., 2012). Farmers simply protect the plants found growing in their farms, an approach termed "farmer managed natural regeneration" resulting into a parkland system (Boffa et al., 1996). Probably due to its slow growth, not many studies have been done on shea tree growth parameters. Recent studies by Okao et al. (2019) gave limelight on the growth performance of shea tree under cultivation. Although natural regenerations are highly promoted by farmers, the species grows slowly taking over a full decade to fruiting. Worse still, because it is an excellent source of fuelwood, many mature trees are converted for charcoal production, modifying further the parkland. These modifications differ in space, intensity and time scale depending on the socio-economic backgrounds of the surrounding communities forming slight variations across its belt.

Much more effort is required by research institutions to establish demonstration plots in form of gene bank collections of shea varieties for the local communities to learn its agronomic practices. One example of such collections in Uganda is the shea gene bank jointly established and managed by the world Agroforestry Centre (ICRAF) and National Agricultural Research Organization (NARO) in Northern Uganda which has proved to the communities that it is possible to grow and manage shea tree in a planted form (ICRAF annual gene bank report 2016).

Shea tree exist in varied morphological forms named differently by the local communities where they grow (Karimbiri et al., 2017). The varied morphological forms such as fruit/seed shapes, color, taste or texture are used to characterize the trees (Mawa et. al., 2016, Gwali et.al, 2015 and Nyarko et.al. 2012). Several approaches have been employed by a number of researchers to characterize the species both at sub-species level to ethnovariety levels (Sanou et al, 2004, Bouvet at el, 2004, Nyarko et al, 2012, Gwali et al, 2013 and Karimbiri et al. 2017). Boadu (2017) differentiated between the West African shea and the Eastern African shea using their oil chemical characteristics. Meanwhile Lovett et al. (2000a), Bouvet et al. (2004), Fontaine et al. (2004), Gwali et al. (2015) employed molecular characterization of shea trees in different parts of Africa. All the above attempts to characterize the species were applied on mature shea trees. It is there now easy to differentiate between the different ethnovarieties using fruit characteristics but the challenge still remains on how to identify the species at seedling stage. This called for the need to phenotype growth traits in the species in order to document their variations when they are still young.

\section{Materials And Methods}

\section{Study area}

Shea fruits were collected from the districts of Katakwi, Otuke, Amoru, Moyo and Arua and seedlings raised in a tree nursery at Ngetta Zonal Agricultural Research and Development Institute (NgeZARDI), Lira district (Fig. 1). Katakwi District is located in the North Eastern region of Uganda covering a total land area of 2,507 square kilometres. It lies longitudes $33^{\circ} 48^{\prime} \mathrm{E}-34^{\circ} 18^{\prime} \mathrm{E}$ and latitudes $1^{\circ} 38^{\prime} \mathrm{N}-2^{\circ} 20^{\prime} \mathrm{N}$. The 
district is 1090 meters (3,550 ft)above sea level. The vegetation of Katakwi District largely comprises savannah grasslands dotted with shrubs and trees. It is generally described as a wood land / shrub land - grassland vegetation dominated by Acacia, Conbretum, Piliostigma, vitellaria paradoxa and Hyperenia species. The mean annual precipitation is $1111 \mathrm{~mm}$ with bimodal rainfal with high peaks during AprilMay and August-October. The dry season extends from December to March with mean temperature of $26^{\circ} \mathrm{C}$. The soils are mainly of ferralitic type (sandy sediments and sandy loam), whichare well drained and friable. Bottomland contains widespread deposits of alluvium.

Otuke district is located $02^{\circ} 30^{\prime} \mathrm{N} 33^{\circ} 30^{\prime} \mathrm{E} / \mathbb{2} 2.500^{\circ} \mathrm{N} 33.500^{\circ} \mathrm{E}$ covering $1,549.8 \mathrm{~km} 2$ (598.4 sq mi) with

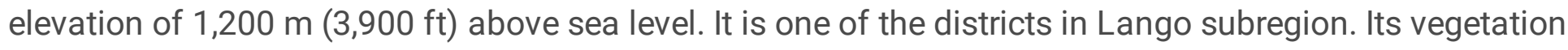
type is predominantly savanah woodland vegetation type interspersed with shea butter trees and other species like combretum, grewiya terminalia, acasia species grow in a mosaic. The mean annual precipitation is $96.2 \mathrm{~mm}$ with bimodal rainfal with high peaks during April-May and August-October. The average annual rainfall in the district varies between $1200-1600 \mathrm{~mm}$ decreasing northwards. The dry season extends from December to March with mean temperature of $27^{\circ} \mathrm{C}$. The main soil type is sandyloam with patches of red ferralitic soils in Otuke districts (Otuke district local government 2015).

Amuru district is located in the northern-most region in Uganda neighbouring South Sudan. It falls within longitudes $31^{\circ} 4^{\prime} 3 " \mathrm{E}$ and $32^{\circ} 3^{\prime} 4^{\prime \prime} \mathrm{E}$ and latitudes $2^{\circ} 7^{\prime} 8 \mathrm{~N} \mathrm{~N}$ and $3^{\circ} 6^{\prime} 3^{\prime \prime} \mathrm{N}$. Its altitude is 1075 meters $(3,412$ $\mathrm{ft}$ )above sea level.Grassland savanna is the dominant vegetation, with bimodal rainfal with high peaks during April-May and August-October, annual rainfall between 900 and $1000 \mathrm{~mm}$. Average temperature is $22^{\circ} \mathrm{C}$. The area is covered with soil types weathered from basement complex gneisses and granites rocks (Nuwategeka and Nyeko (2017). The district is mostly inhabited by the Acholi group of people.

Moyo District is located in the north-western corner or West Nile region of Uganda. Moyo district is 865 meters (2,593 ft)above sea level. It has two rainy seasons which occur in April (short rainy season) and between August and October (major rainy season) and it receives about 1,267 mm of annual rainfall. The vegetation type in moyo district is predominalty woodland interspersed with shea butter treestowards the boarder with the Republic of South Sudan.

Arua district lies between latitude $2^{0} 3^{0} \mathrm{~N}$ and $3^{0} 5^{0} \mathrm{~N}$ and longitude $30^{\circ} 30^{\prime} \mathrm{E}$ and $31^{\circ} 30^{\prime} \mathrm{E}$ in the north western part of Uganda. The district covers a total area of 4274.13 Sq. $\mathrm{km}$ of which $87 \%$ of the land is arable. The district mainly comprises of rolling plains rising from the Nile floor in the rift valley $(600 \mathrm{~m}$ above sea level) to the Congo - Nile water divide (1200 to 1400 meters above sea level). Arua district has a bi-modal rainfall pattern with light rains between April and October. The wettest months are august and September, the average annual rainfall is $1250 \mathrm{~mm}$. The soils covering most of the district are mainly ferralitic and sand loams with fine textile with rather loose structure, which are easily eroded and leached. Most soils are acidic. Soil types in the district include: Yellow - red sandy, clay loams latosols varying from dark grey to dark which are slightly acidic and mainly derived from granite, gneissic and sedimentary rocks. They occur on gently undulating - hilly topography. Brown - yellow clay loams with 
laterite horizon with a variety of dark brown to dark greyish brown, which are slightly acidic. These occur on flat ridge tops or as of undulating

Lira district is 1,080 meters ( $3,540 \mathrm{ft})$ above sea level. The vegetation type in lira district is savanah woodland interspersed with shea butter trees the predominant tree species are the combretum, vitellaria, terminalia, casia, grewiya species. The mean annual precipitation is $94.2 \mathrm{~mm}$ with bimodal rainfal with high peaks during April-May and August-October. The average annual rainfall in the district varies between 1200-1600 mm decreasing northwards. The dry season extends from December to March with mean temperature of $26^{\circ} \mathrm{C}$. The geological formations in Lira district is basement complex (mainly undifferentiated acid gneiss) covering most of the district. The site at NgettaZARDI was selected due to the presence of a research station that is situated within shea tree growing region that can provide an ample growing conditions for the experimental shea tree plantlets. NgettaZARDI is also place near urban settlement where shea trees were depleted and this gives opportunity for isolation of the breeding plants from contamination with other none superior materials from within the area.

\section{Plant Materials And Planting Medium}

Only mature and freshly fallen ripe undamaged shea fruits were carefully picked directly from under 180 jointly selected seed trees across the study sites. A total of 1204 fruits were collected during the month of June 2018 and transported to NgeZARDI for processing before sowing. The fruit pulps were then removed using fingers and each ethnovariety put in small cloth bags to avoid mixing. These were then placed in a thick gunny bags soaked with water and kept under cool shade for two weeks to allow kennels to crack before sowing directly into polythene pots filled with planting medium. Up to sixteen ethnovarieties were collected from the five districts and sown.

The planting medium composed of a mixture of $70 \%$ top forest soil and $30 \%$ clay soil. After mixing thoroughly, the medium was filled into polythene pots 6 inches width by 8 inches length, sealed at the bottom and punctured to let off excess water to avoid seed rot before germination,

\section{Experimental Design}

The kernels were sown in a randomized incomplete complete block design with three replicates to measure the variations that existed among the experimental units after fourteen days when the radicles had cracked the kernels. The kernels were sown directly into the pots filled with the growing medium and watered twice a day with 10 Liters of water per square meter for a period of six months when it was believed that most of the seeds had germinated.

\section{Data Collection}


The seeds were germinated and kept in the nursery at NgeZARDI for 18 months to attain required height of $\geq 15 \mathrm{~cm}$ taken to the highest leaf point. The following were recorded from the seedlings for phenotypic analysis: date for first seedling sprout, Root collar diameter, seedling height, number of leaves developed, leaf length, leaf width and petiole length. Measurements were taken to the nearest millimetres monthly for eighteen months. The seedlings were then planted in two different sites as shea tree Breeding Seed Orchard intended for genetic trial of superior phenotypes for mass production of genetically improved materials.

\section{Data analysis}

Data were analysed using $\mathrm{R}$ package Shiny to run analyses through $\mathrm{R}$ environment and functions. Both genetic and phenotypic cluster analysis to determine the similarity groupings of the two methods. Principal Component Analysis and ANOVA were also run to determine the variation among the five shea populations.

\section{Results}

\section{Seed germination}

A total of 1204 biological seeds were sown and germination started after three weeks and continued up to the tenth week from the date of sowing. The overall germination percentage of the whole seed lot was $62.8 \%$. The seed lots germinated between the 2nd of July 2018 and 14th December 2018. Shea seed germination indicated that, Arua population had the highest (61.2\%) germination percentage followed by Amuru (58.3\%) population (Fig. 2).

Arua, Amuru and Otuke seed lots had three weeks' peak germination implying that the seed lots were more viable and therefore had longer germination time which increased their germination percentages (Fig. 3). The average shea seed germination rate per month was $8.7 \%$. The seeds gained highest germination rates in the second month $(16.1 \%)$ after sowing from which it started decreasing till the sixth month $(2 \%)$ from which no more germinations were recorded among the seed lots. The difference in seed germination among the 5 seed lots was significant $(P \leq 0.001)$.

All the seed lots gained highest germination vigor in the second and third months. Moyo seedlot had the highest germination vigor where over $50 \%$ of the seeds had germinated by the second month. Whereas Katakwi seedlot registered the lowest seed vigor (Fig. 3).

\section{Seedling growth}

Hairy variety, Thin pulped, hard pulped and tasteless pulped ethnovarieties vigorously grew and surpassed the other ethnovarieties. These were still the same seedlings which had larger root collar diameters and leaf size. On the other hand, Dwarf tree; black seeded and red seeded ethnovarieties had much inferior growth traits than the rest. Seedling height; root collar diameter; number of leaves; leaf 
length; leaf width and petiole length were recorded and presented in Fig. 4 below. The tallest plantlets were from Arua population, they also had more leaves per plant.

Meanwhile populations from Arua and Moyo had the largest leaf sizes and longer petiole lengths were recorded from Moyo, Arua and Amuru populations. Otuke and Katakwi populations generally had lower expression of the studied traits as compared to the other three populations.

Given in Table 1 below are the average performance of the different growth traits.

Table 1

Comparison of growth traits among shea tree ethnovarieties measured at 18 months after sowing.

\begin{tabular}{|c|c|c|c|c|c|c|c|}
\hline Ethnovarieties & $\begin{array}{l}\text { Traditional } \\
\text { (Luo) } \\
\text { nomenclature }\end{array}$ & $\begin{array}{l}\text { Height } \\
\text { (cm) }\end{array}$ & $\begin{array}{l}\text { Root collar } \\
\text { diameter } \\
(\mathrm{mm})\end{array}$ & $\begin{array}{l}\text { No. of } \\
\text { leaves }\end{array}$ & $\begin{array}{l}\text { Leaf } \\
\text { length } \\
\text { (cm) }\end{array}$ & $\begin{array}{l}\text { Leaf } \\
\text { diameter } \\
\text { (cm) }\end{array}$ & $\begin{array}{l}\text { Petiole } \\
\text { length } \\
\text { (cm) }\end{array}$ \\
\hline Sweet pulped & Malim & 5.49 & 4. 18 & 4 & 13.55 & 6.16 & 1.17 \\
\hline Soft pulped & Apocopoco & 4.51 & 3.61 & 3 & 12.76 & 5.19 & 1.08 \\
\hline Hard pulped & Acogo & 5.62 & 4. 24 & 4 & 12.17 & 5.35 & 1.25 \\
\hline Small seeded & Lagili & 4.99 & 3.71 & 3 & 11 & 5.05 & 0.94 \\
\hline Oval fruited & Acula & 5.17 & 3.56 & 4 & 11.54 & 5.35 & 1.02 \\
\hline $\begin{array}{l}\text { Astringent } \\
\text { tasted }\end{array}$ & Yao cot & 5.06 & 4. 12 & 3 & 12.34 & 5.7 & 1.57 \\
\hline Round fruited & Alulung & 4.8 & 3.45 & 3 & 12.26 & 5.44 & 1. 21 \\
\hline Thin pulped & Lo'koroc* & 5. 68 & 4. 18 & 3 & 14. 17 & 6.16 & 1.51 \\
\hline Hairy & Jayer & 6. 02 & 4. 15 & 3 & 17. 07 & 6.67 & 1.4 \\
\hline $\begin{array}{l}\text { Elliptical } \\
\text { fruited }\end{array}$ & Maboco & 5.37 & 3.91 & 3 & 14. 20 & 7.9 & 1.3 \\
\hline $\begin{array}{l}\text { Tasteless } \\
\text { pulped }\end{array}$ & Yao mabot & 5.63 & 3.92 & 3 & 13.44 & 5.58 & 1.38 \\
\hline $\begin{array}{l}\text { Big oval } \\
\text { fruited }\end{array}$ & Yao Madongo & 5.39 & 3.63 & 4 & 12.33 & 5.52 & 1.23 \\
\hline Tiny seeded & Lalet & 5.16 & 3.86 & 3 & 12.81 & 5.5 & 1.11 \\
\hline Black seeded & Macol/Molilo & 3.97 & 2. 93 & 2 & 10.37 & 4.3 & 0.86 \\
\hline Red seeded & Aremo & 4.49 & 2.77 & 2 & 7. 92 & 3.58 & 0.82 \\
\hline \multirow[t]{2}{*}{ Dwarf } & Yao wigweng & 3.17 & 2.7 & 3 & 7.69 & 3.71 & 1.31 \\
\hline & *Ateso & & & & & & \\
\hline
\end{tabular}


Average growth trait measurements for the different ethnovarieties were presented in Table 1. There were some few ethnovarieties which exhibited better phenotypic growth traits as compared to the rest. Hairy $(6.02 \mathrm{~cm})$, Thin pulped $(5.68 \mathrm{~cm})$ Tasteless fruited $(5.63 \mathrm{~cm})$ and Hard pulped $(5.62 \mathrm{~cm})$ ethnovarieties were taller than the rest meaning they are fast growing. These were same ethnovarieties that had the largest root collar diameters and leaf size indices. These ethnovarieties could also be selected for when selecting traits for shea tree breeding programme in Uganda.

\section{Relationship and correlations among the growth traits}

The regression lines in Fig. 4 show a strong positive relationship between root collar diameter and shea tree height and leaf size index. It reveals that $85.9 \%$ of the variation in shea tree leaf size and $93 \%$ of the variation in shea tree height respectively were explained by the root collar diameter. The linear regression equation for shea tree plantlet height is therefore presented as $y=0.3787+12.671 x$ and for leaf size index $y=0.6483+15.413 x$.

It is evident that shea tree height and leaf size index exponentially increased with increasing root collar diameter (Fig. 4). Leaf size index increased at a slightly higher rate than the tree height.

Correlation of the five traits showed that root collar diameter is more correlated to leaf length (0.4) than shear tree height ((0.3) table 2). There was a weak correlation between tree height and leaf width to the rest of the traits. Number of leaves per plant had a weak negative correlation with leaf width and petiole length ( -0.04 and -0.02 respectively) but a weak positive (0.09).

Table 2: Plot of pairwise Pearson correlations and regressions among traits and their scatter plot matrices. The phenotypic data for each trait was used for the analysis.

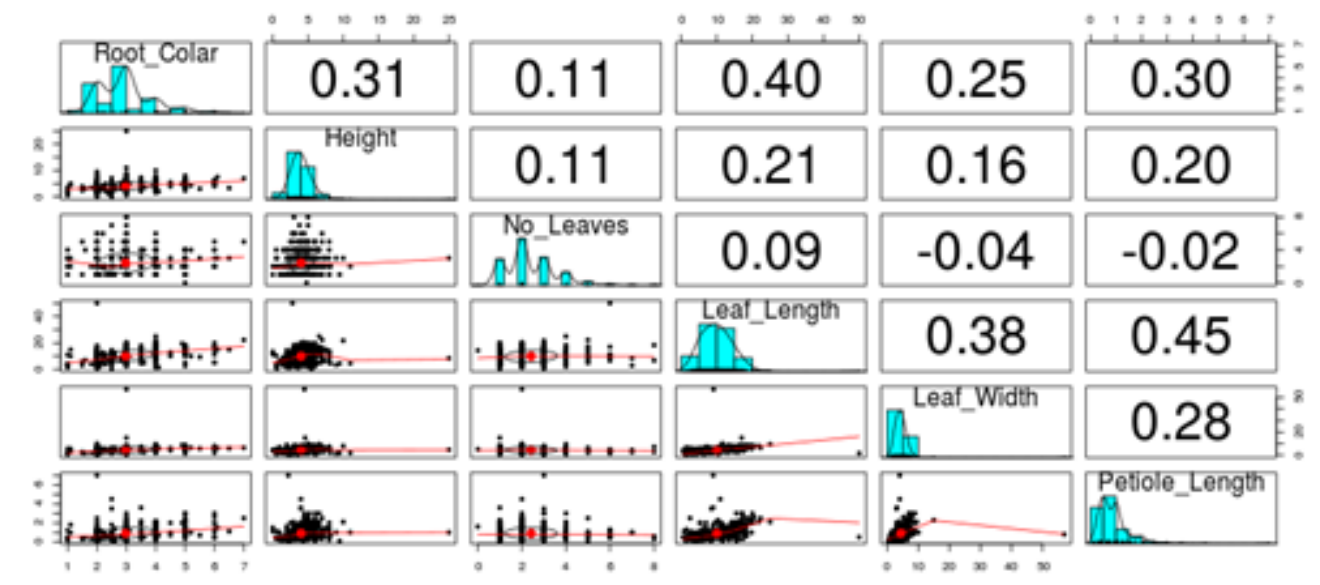

There was however a relatively higher correlation (0.45) between the leaf length and petiole length. Root collar diameter and number of leaves on a plant had individuals with a relatively very low and very high parameters making it possible to do directional selection for various purposes. Besides tree height and leaf length, the rest of the traits were negatively skewed (skewed to the left). All the plantlets had more less the same leaf width except on plantlet which was an outlier. Analysis of PC1 explained $86.3 \%$ of the 
variance while PC2 explained $4.8 \%$ totaling to $91.1 \%$ of the whole phenotypic variation in the population (Fig. 4). It is also important to note that the majority of the population were clustered into only one aggregated cluster with some few outside the cluster.

Almost all lines shown in Fig. 5 were grouped together in one side of the graph indicating little differentiation among them based on the five phenotypic traits. Infact their Jaccard index for the growth traits was 0.92 indicating that the plantlets were $92 \%$ similar given their phenotypic growth traits. This proved how similar they were in phenotypic composition that resulted in the majority forming one cluster with very few phenotypes (8\%) dissimilar. This as in contrary to the hierarchical clustering based on the SNP data in Fig. 6 where individuals clustered themselves within a population according to their genetic similarities and nearest relatives.

The clusters were divided into groups of similar colors according to areas of origin although some few members with different colors identified with different clusters. Three major clusters were formed meaning there are three populations according to SNP data. Amuru, Moyo, Arua, some few Katakwi and Otuke members formed the first major population; Otuke, Moyo and few Katakwi members formed the second population and Katakwi population the third. In Fig. 6, the different colors show different populations.

\section{Discussion}

\section{Seed germination and seedlings growth}

Arua population generally exhibited germination percentage and growth rates than the rest of the populations in germination percentage and growth. The seed lots varied significantly in germination vigor and growth performance although they did not significantly differ in germination percentage. Seed germination vigor is a good predictor of seed lot quality and health. It is an indication that the seed lot quality has not deteriorated and therefore still retains good physiological potential for vigorous growth. It also implies that the species or seed lot is well adapted to the environment (Birkinshaw et al. 2011). This study however, considered seedlings raised in similar environment thus negating claims due to environmental variation. We propose that the variation in growth performance could be genetic rather than environmental. Where such variations exist given similar treatments such as variation in seedling height and root collar diameter of seedlings grown under similar conditions suggests that the variations could be due to additive genetic factors (Loha et al. 2006). The genetic effects on the seedlings could have been inherited due to the narrow sense heredity which is important for shea tree breeding (improvement). This is in line with Souza et al (2019) who reported that efficiency of early selection depends mainly on the early-mature correlation and the heritability of growth traits in rubber tree in Brazil. Related studies by Ding et al. (2020) recommended selection of Populus genotypes with taller heights and larger diameter growth for the species improvement. Meanwhile it can also ne noted that environment can greatly affect growth performance in species, this is not additive and therefore can change with changing environment. Growth medium like compost amended medium may yield better 
results than other medium (Daldoum et al. 2013). Infact similar tree species from different sources grown in one environment and conditions can still show some variation in growth traits indicating that there are other things in control than the environment. In a bid to rule out this claim, Azad et al. (2014) grew Cordia Africana and Azadirachta indica seedlings collected from 19 provenances in one location and registered different growth rates beyond simply phenotypic or environmental characteristics. This is true with the expression that any phenotype is as a result of genetic and environmental factors; $(P=G+E)$. Growing different populations within a similar environment eliminates the claims on environmental effects leaving additive genetic effects at play.

\section{Seedlings growth traits}

Relationship between collar diameter and height growth and leaf size index showed a strong positive correlation at juvenile stage indicating that diameter growth, height growth and leaf development uniformly took place. The diameter growth increased with height and leaf growth confirming existence of larger root collar diameter growth which was population based. Populations from different regions can differ in their trait performance even if they are the same species. This is in line with Abutaba et al (2015) who reiterated that variation in root collar diameter of the same species from Western, Central and Eastern Sudan was due to better adaptive and hereditary traits within the different populations. Other related studies by Okao et al, (2019) and Ayari et al, (2012) associated faster tree growth to bigger crown size/crown biomass partly contributed to by the available leaf quantity. Infact the report by Okao et al. (2019) indicated that broad lived trees from Palabek were growing faster than the rest of the accessions.

Despite of all the above, tree diameter has been registered as the best tree growth estimator better than any other tree growth parameters (https://rtectreecare.com/dbh-calculator/ Accessed 4/17/2020).

\section{Relationship and correlations among the growth traits}

Hierarchical clustering in (Fig. 8) revealed three populations performed from SNP data of five populations (Katakwi, Otuke, Amuru, Moyo and Arua). Katakwi population formed a standalone population although few of its members were more similar with members in the second cluster. The population is located in the Eastern lowlands agroecological zone separated from the second population/cluster (Otuke) by a wide swamp that feed into lake Kyoga which could have disrupted genetic flow between the two populations. Although pollination in shea is mainly carried out by bats and birds that can fly over such swamps. Land use changes that have claimed a large numbers of shea tree stands through clearance for agricultural expansion has further more widened the gaps between the two populations that pollen cannot be transported from one population to another. This could more difficult with shea fruits which are heavier to be carried longer distances. This could have caused isolated population clusters that encouraged inbreeding among close relatives resulting in strong similarity within the population but dissimilarity with other populations. This is in line with the report by Bijlsma et al 1991 who reported substantial genetic differentiation between smaller populations and larger populations of Salvia pratensis and Scabiosa columbaria. The second cluster comprised majorly of Otuke population with a mixture of some Katakwi and Arua genotypes. Otuke population however, had some combination from 
Katakwi and Arua suggesting genetic similarity with those genotypes. These could have been due to gene flow that caused the transfer of genetic materials form other populations into Otuke population arising from movements of people across the districts. Since shea tree is a widely out crossing species, recombination during cross pollination could have had much more effect that caused the similarity of such genotypes to those in Katakwi and Arua populations (Gwali et al. 2012). Likewise, the allele frequencies of such genotypes must have been similar due to the recombination effects working within the population. This could be true given the geographical distance from Arua district (West Nile region) to Otuke district (Lango region) separated by a rift valley and river Nile.

The third cluster however, comprised of aggregation of populations from Moyo, Arua and Amuru districts. Since Arua and Moyo are within the same agroecological and political region where communities easily interact, there is a high possibility that genetic materials could have been moved from one location to the other facilitating mixing, although cross pollination could have also played a big role. On the other hand, Moyo district is kind of land locked district with exit and entry routes through Arua to the south and Amoru to the East. It is therefore most likely that genetic materials moved from these populations as communities traveled and got mixed within the original local populations across the districts. Following the history of the Luo migration from Bar -El - Gazzel (Equatorial province in Sudan) through Amoru point, some shea tree genetic materials could have been dispersed to Amoru which later on found their way to West Nile (Moyo and Arua) since the Alur tribes in West Nile was as a result of intermarriages between the original West Nilers and the Luo.

\section{Conclusion}

There was considerable variation in germination and growth performance among the five she tree populations under this study. The variations within and between populations indicate existance of some few genotypes with both quite good growth traits that could be selected for faster growth and thus early maturity important for shea tree improvement in Uganda. We therefore recommend that directional selection could be targetted to conserve both good growth performers and poor performers with other promissing traits of interest and conservation. The significant difference in the gernination and growth performance among the poulations suggest that the seedlings exhibited different physiological and genetic characteristics that made them to perform differently.

\section{Declarations}

\section{Ethics approval and consent to participate}

Not applicable

\section{Consent for publication}

Not applicable 
Availability of data and material

The datasets used and/or analyzed during the current study are available from the corresponding author on reasonable request.

\section{Competing interests}

The authors wish to declare that there is no any form of conflict of interest.

\section{Funding}

This work was supported through a collaborative project between the World Agroforestry (ICRAF) and National Forestry Resources Research Institute (NaFORRI) under Genebank Platform (GCDT - 1213).

\section{Authors' contributions}

JBO, SM, OTL and OCA conceived the concept; JBO, OTL and GS designed the work; JBO, OM and KH acquired and analyzed the data; JBO, GS, OTL, OJBL interpreted the data; JBO drafted the manuscript; AM, GS, OTL, OJBL and OCA substantively revised and modified the paper

\section{Acknowledgments}

The authors would like to thank the staff and administration of Ngetta Zonal Agricultural Research and Development Institute (NettaZARDI), Ms. Gloria Mutoni, the Agroforestry Technician, for her tireless contribution towards managing the experiments and collecting the data used for analysis and writing this paper.

\section{References}

1. Abutaba YIM, Eldoma AMA, Mohamed SM (2015) Variations in Nursery Seedlings Growth Performance of Azadirachta Indica Provenances in Sudan. The Journal of Agriculture Natural Resources Sciences 2(2):475-447

2. Asante WJ, Banidiyia MA, Tom-Dery D (2012) Effect of planting depth on the germination and initial growth and development of shea (Vitellaria paradoxa C.F. Gaertn.). Int J Biosci (IJB) 2:146-152

3. Ayari A, Zubizarreta-Gerendiain A, Tome M, Tome J, Garchi S, Henchi B (2012) Stand, tree and crown variables affecting cone crop and seed yield of Aleppo pine forests in different bioclimatic regions of Tunisia. Forest Systems 21(1):128-114

4. Azad Md S, Nahar N, Mollick AS, and Matin Md.A (2014) Variation in Seedling Growth of Tamarindus indica (L.): A Threatening Medicinal Fruit Tree Species in Bangladesh. Journal of Ecosystems Article ID 270956:9. pages http://dx.doi.org/10.1155/2014/270956 
5. Bijlsma R, Ouborg NJ, van Treuren R (1991) Genetic and phenotypic variation in relation to population size in two plant species Salvia prantensis and Scabiosa columbaria. In: Seitz A, Loeschcke V (eds) species conservation: A population - Biological Approach. Advances in Life Sciences. Birkhauser, Basel

6. Birkinshaw C, Andrianjafy M, Rasolofonirina J-J (2011) Survival and growth of seedlings of 19 native tree and shrub species planted in degraded forest as part of a forest restoration project in Madagascar's highlands. Madag Conserv Dev 4(2):128-131

7. Boffa JM, Yaméogo G, Nikiéma P, Knudson DM (1996) Shea nut (Vitellaria paradoxa) production and collection in agroforestry parklands of Burkina Faso. In: Leakey RRB, Temu AB, Melnyk M, Vantomme $\mathrm{P}$ (eds) Domestication and commercialization of non-timber forest products in agroforestry systems. Non-wood Forest Products 9. FAO, Roma, pp 110-122

8. Boffa J-M, Yameogo G, Nikiema P, Taonda JB (2000) Shea Nut (Vitellaria paradoxa) Production and Collection in Agroforestry Parklands of Burkina Faso. Department of Forestry and Natural Resources, Purdue University, West Lafayette, p 13

9. Bouvet J-M, Fontaine C, Sanou H, Céline C (2004) An analysis of the pattern of the genetic variation in Vitellaria paradoxa using RADP markers. Agroforestry systems $n^{\circ}$ 60:61-69

10. Bundock PC, Eliott FG, Ablett G, Benson AD, Casu RE, Aitken KS, Henry RJ (2009) Targeted single nucleotide polymorphism (SNP) discovery in a highly polyploid plant species using 454 sequencing. Plant Biotechnol J 7:347-354

11. Byakagaba P, Eilu G, Okullo JBL, Tumwebaze SB, Mwavu EN (2011) Population structure and regeneration status of Vitellaria paradoxa (C.F.Gaertn.) under different land management regimes in Uganda. Agric J 6(1):14-22

12. Daldoum MA, Daldoum, Hakim AA (2013) Growth Performance of Four Acacia Tree Seedlings Raised in Silt Soil Amended with Compost JONARES, Vol. 1, pp 23-28

13. Ding C, Hamann A, Yang R-C, Brouard JS (2020) Genetic parameters of growth and adaptive traits in aspen (Populus tremuloides): Implications for tree breeding in a warming world. PLoS ONE 15(3):e0229225

14. Gwali S, Okullo JBL, Eilu G, Nakabonge G, Nyeko P, Vuzi P (2011) Folk classification of Shea butter tree (Vitellaria paradoxa subsp. nilotica) ethno-varieties in Uganda. Ethnobot Res Appl 9:243-256

15. Gwali S, Vaillant AG, Nakabonge Okullo JBL, Eilu E, Muchugi A (2015) Genetic diversity in shea tree (Vitellaria paradoxa subspecies nilotica) ethno-varieties in Uganda assessed with microsatellite markers. Forests, Trees and Livelihoods. Volume 24, Issue 3 pp 163-175

16. Gwali S, Nakabonge G, Okullo JBL, Eilu E, Nyeko P, Vuzi P (2012) Morphological variation among shea tree (Vitellaria paradoxa subsp. nilotica) 'ethno-varieties' in Uganda Genetic. Resources Crop Evolution 59:Issue 8, pp 1883-1898

17. https://rtectreecare.com/dbh-calculator/

18. Jasaw GS, Osamu S, Takeuchi K (2015) Shea (Vitellaria paradoxa) Butter Production and Resource Use by Urban and Rural Processors in Northern Ghana. Sustainability ISSN 2071 - 1050 
19. Kambo D, Danby RK (2018) Factors influencing the establishment and growth of tree seedlings at Subarcticalpine treelines. Ecosphere 9(4): e02176.10.1002/ecs2.2176

20. Loha A, Tigabu M, Teketay D, Lundkvist K, and Fries A (2006) Provenance variation in seed morphometric traits, germination and seedling growth of Cordia africana Lam. New Forest 32(1):7186

21. Mawa K, Marlène E, Barbara V, Alessandra G (2017) Exploring local knowledge and preferences for shea (Vitellaria paradoxa) ethno varieties in Southwest Burkina Faso through a gender and ethnic lens. Forests, Trees and Livelihoods Volume 26, - Issue 1 pp 13-28

22. Nyarko G, Mahunu GK, Chimsah FA, Yidana JA, Abubakari AH, Abagale FK, Quainoo A, Poudyal M (2012) Leaf and fruit characteristics of Shea (Vitellaria paradoxa) in Northern Ghana. ResPlant Biol 2(3):38-45

23. Okao M, Odoi JB, Okia C (2019) Growth performance of Shea nut tree (Vitellaria paradoxa) collections in an ex-situ Trial plot- Lira District, Uganda. IJRDO - Journal of Agriculture and Research Volume-5 | Issue-4 | April,2019

\section{Figures}

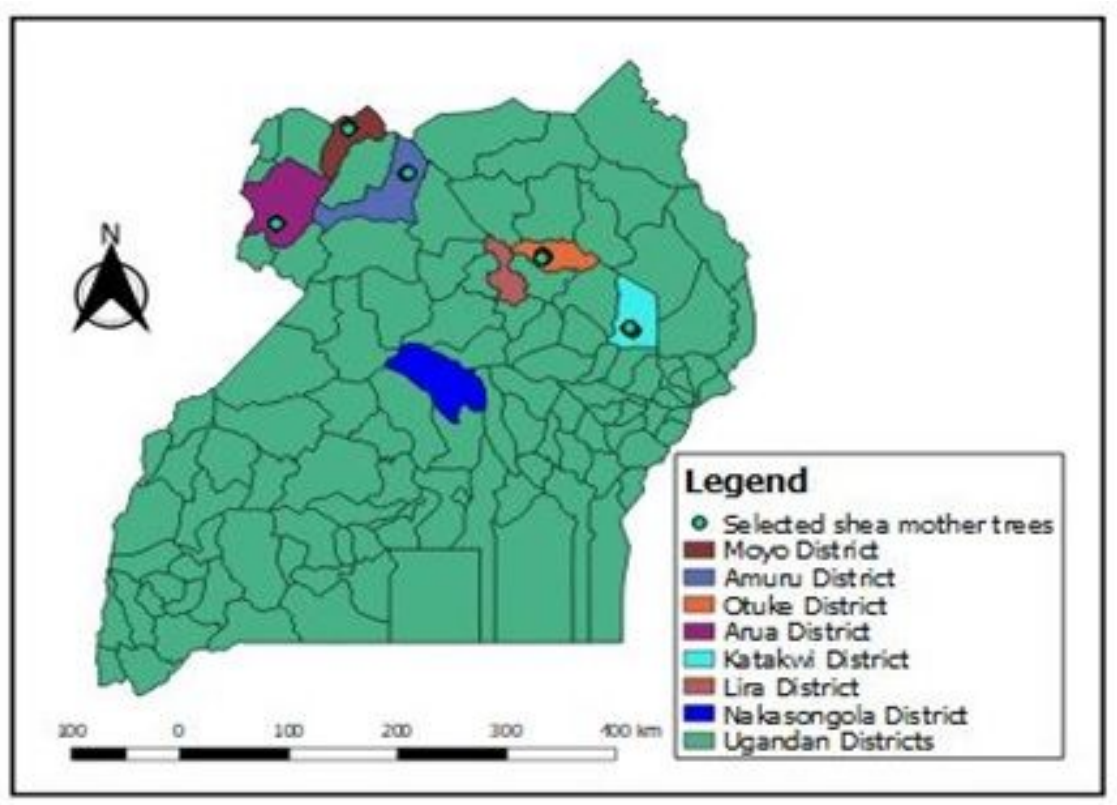

\section{Figure 1}

Map of Uganda indicating location of study sites. The dots in the study sites show the actual location within the districts where shea trees seeds were selected from. 


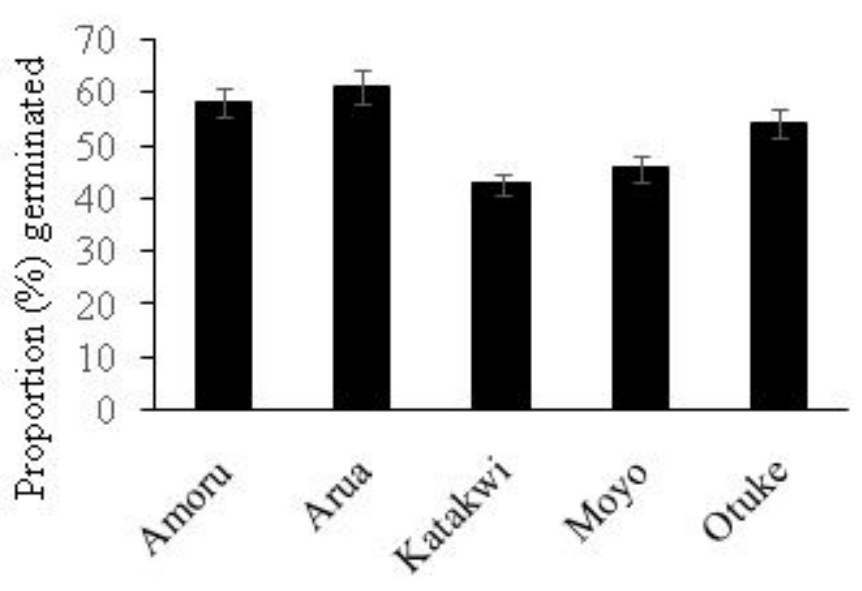

Shea seed lots

Figure 2

Proportions of germinated shea tree seeds sown in NgettaZARDI tree nursery in mid-June 2018. The seeds were left in the nursery for six months when no more germination could be recorded.

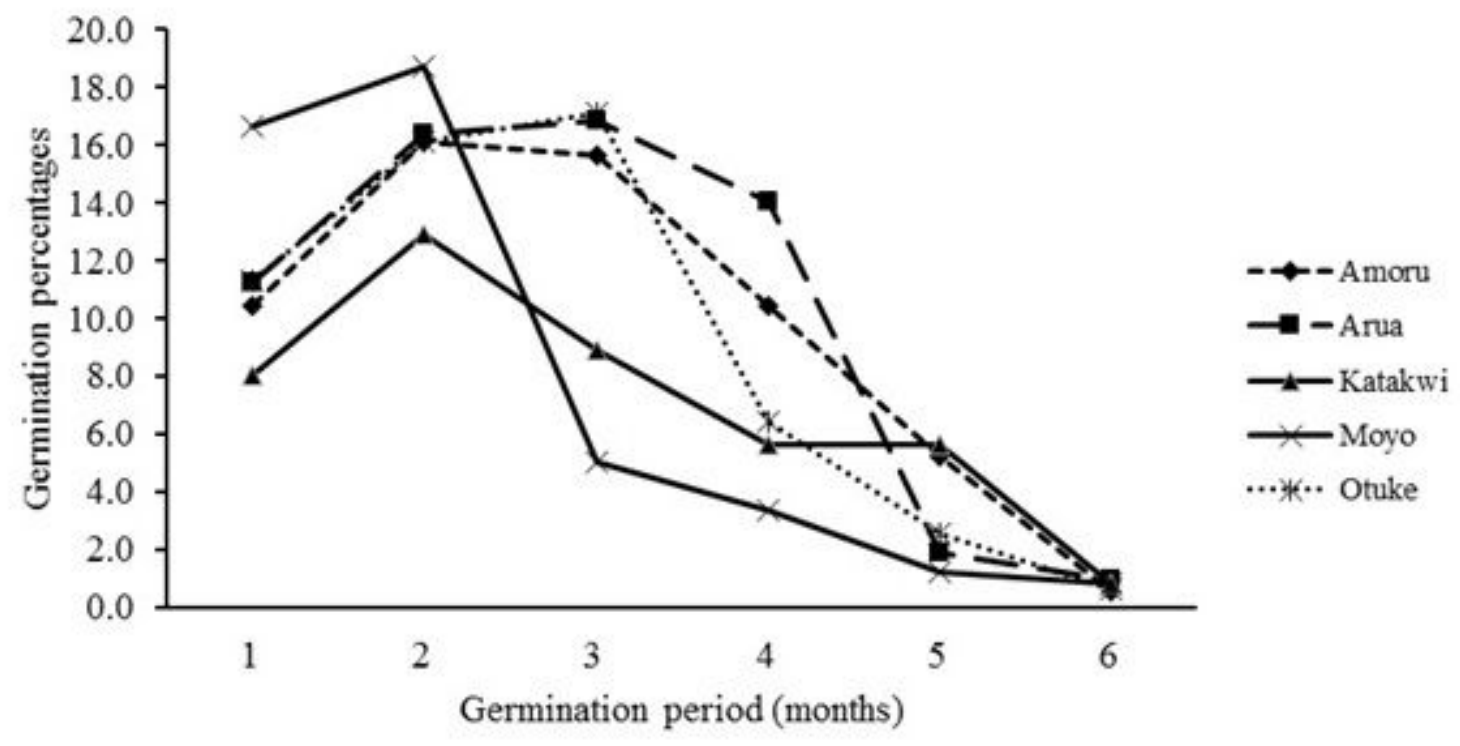

Figure 3

Shea tree seeds monthly germination percentage for the five seed lots collected from Arua, Amuru, Katakwi, Moyo and Otuke districts. A total of 1204 biological seeds from sixteen ethnovarieties were sown in mid-June 2018. 


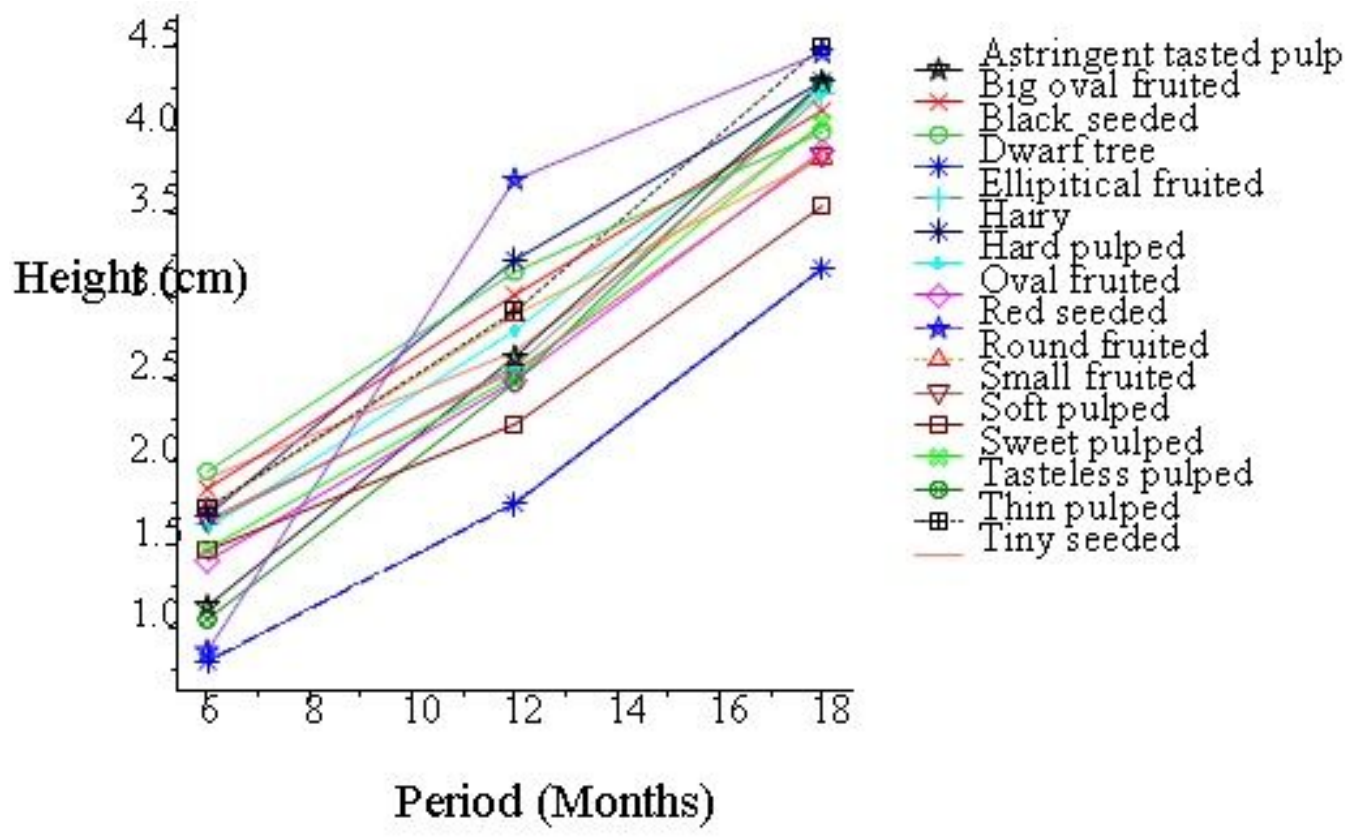

Figure 4

Growth performance of the sixteen-shea tree ethnovarieties in Uganda. The plantlets were measured thrice at an interval of six months after germination

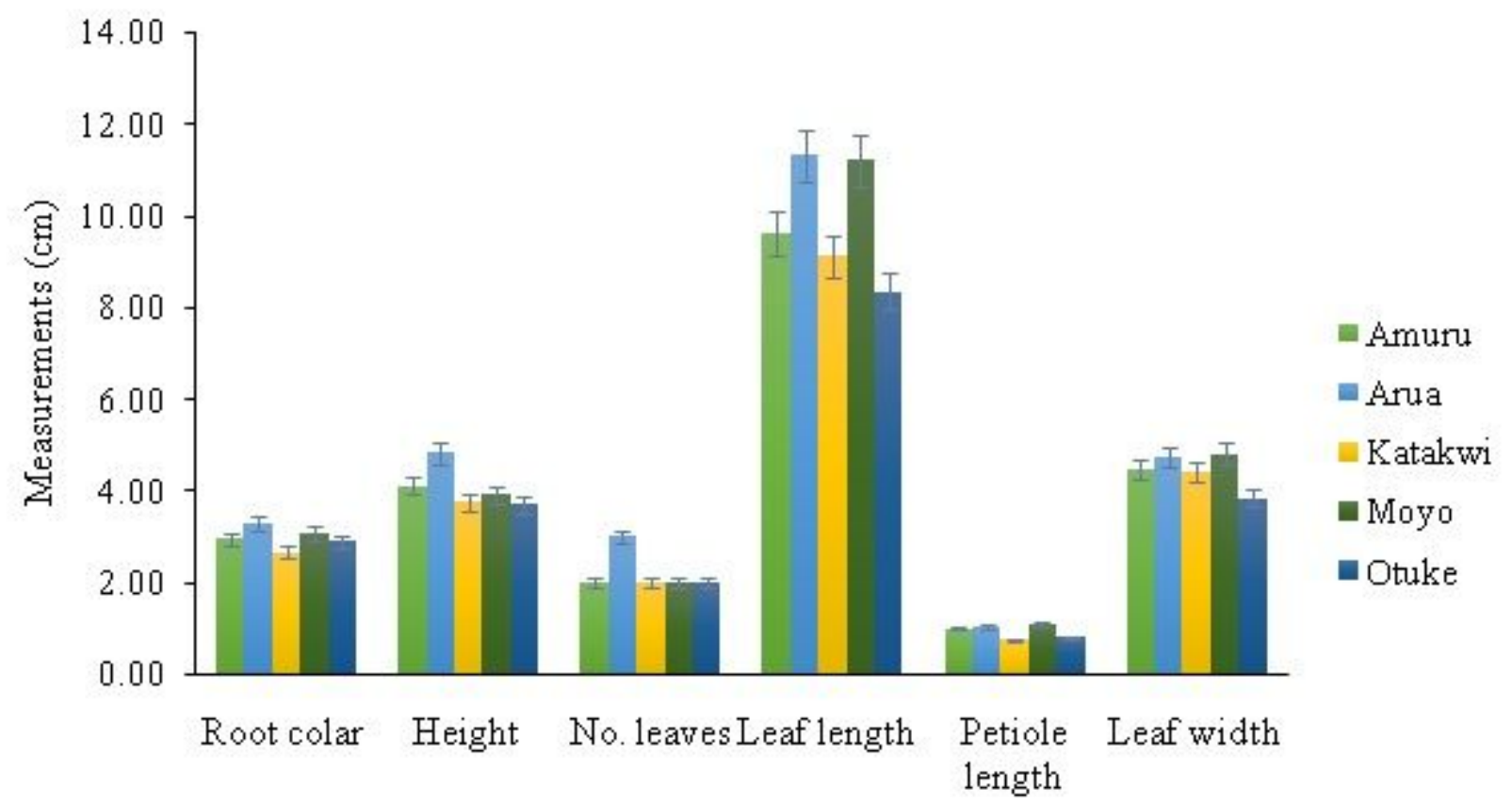

Growth traits

\section{Figure 5}

Shea tree phenotypic growth traits for five populations measured at 18 months. The root collar diameter $(\mathrm{mm})$ was taken right where the stem leaves the soil, leaf length was taken from the point of attachment to the stem to the leaf apex and the leaf width was taken from the widest point of the leaf lamella. 


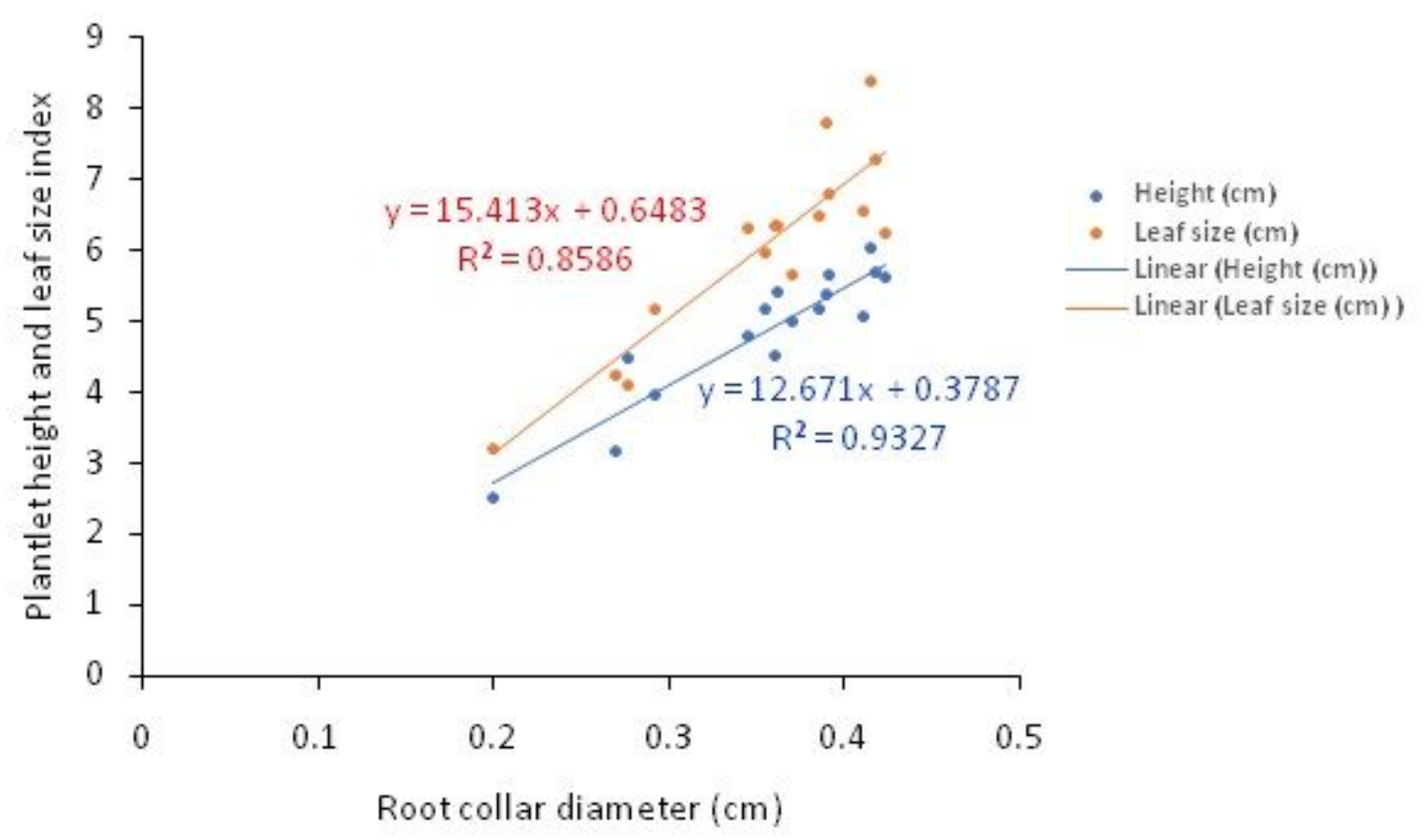

Figure 6

shows regression of shea tree the root collar diameter against shea tree height and leaf size indexin five populationsplantlets. The dots/points in the figure represents each shea tree family, they represent either average shea tree root collar diameter on the $\mathrm{X}$-axis and the average shea tree height and leaf size index of the plantletson the $\mathrm{Y}$-axis. The leaf indices were derived by getting the averages of each leaf length and widthto get a single parameter referred to here as the leaf index.

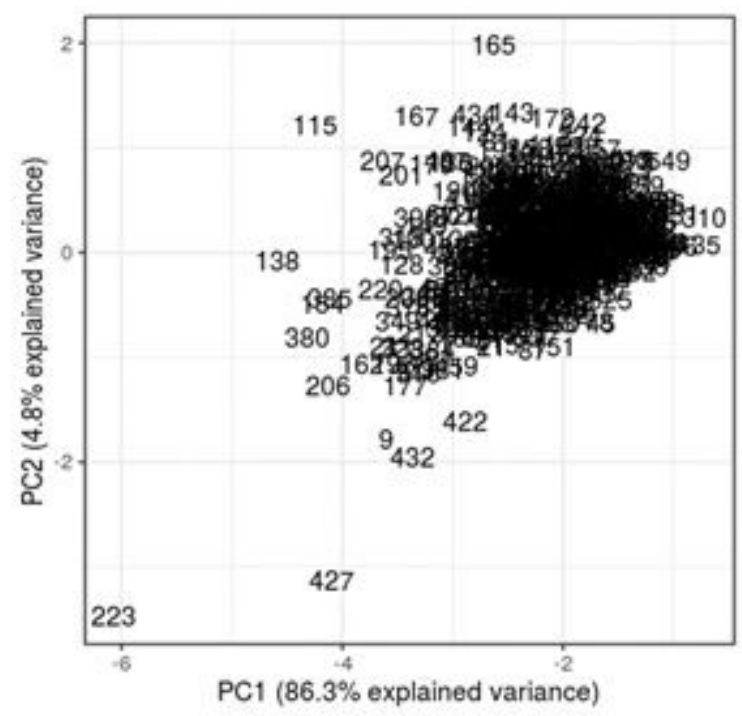

\section{Figure 7}

Hierarchical clustering of shea tree lines (numbers onset) based on their phenotypic values for the 5 traits which was carried out using the web-based platform Glabstat (https://www.glabstat.com/analyze-your- 
data) that uses $\mathrm{R}$ package Shiny to run analyses through $\mathrm{R}$ environment and functions.

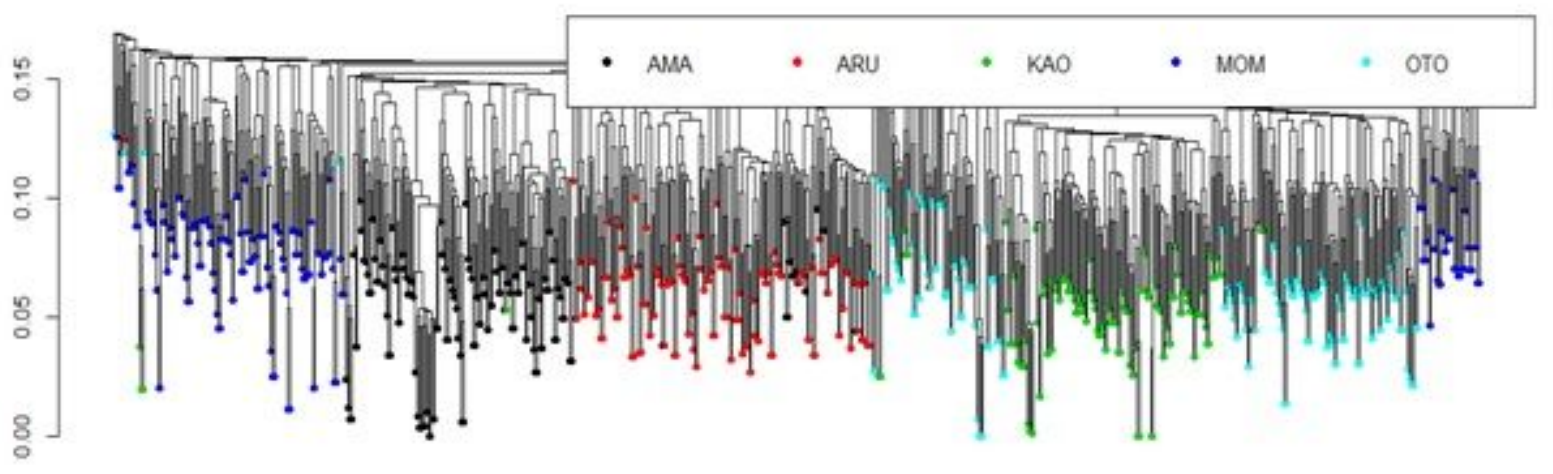

Figure 8

Hierarchical clustering performed on the Duplicate removed SNPs data using the R package SNPRelate. It shows how the different population (colors) clustered based on their genetic similarities and dissimilarities. 